\title{
12-PULSE RECTIFIER WITH TWO DCM BOOST-TYPE HALF-CONTROLLED BRIDGES FOR VARIABLE-INPUT-FREQUENCY APPLICATIONS
}

\author{
João Carlos Pelicer Junior ${ }^{1}$, Angelo César de Lourenço ${ }^{2}$, Luis De Oro Arenas ${ }^{3}$, Falcondes Mendes de \\ Seixas $^{4}$ \\ ${ }^{1}$ Federal Institute of São Paulo - IFSP, Sorocaba - SP, Brazil \\ ${ }^{2}$ Federal Institute of Education, Science, and Technology of Mato Grosso do Sul, Campo Grande - MS, Brazil \\ ${ }^{3}$ São Paulo State University, Institute of Science and Technology of Sorocaba, Sorocaba - SP, Brazil \\ ${ }^{4}$ São Paulo State University, Ilha Solteira - SP, Brazil \\ e-mails: joao1.pelicer@gmail.com, angelo.lourenco@ifms.edu.br, luis.arenas@unesp.br, falcondes.seixas@unesp.br
}

\begin{abstract}
This paper presents the analysis of the integration of two three-phase half-controlled boost converters, operating in discontinuous conduction mode (DCM), to the auto-connected 12-pulse rectifier. The proposed structure shows a reduced current harmonic content compared to the traditional 12-pulse rectifiers, being a simpler and effective alternative to using rectifiers with higher pulse numbers. It also presents a greater range of possibilities for regulating the output voltage, without the use of synchronization algorithms or rigorous control techniques, being possible to send to all controlled switches, the same command signal, resulting in a simpler logic. Another advantage of using the proposed technique is the employment of a single-loop voltage control scheme, reducing the computational and financial cost by eliminating some elements such as current sensors. Moreover, the proposed strategy provides soft commutations (Zero-Current-Switching - ZCS). In this work, a small-scale prototype was implemented, aiming to obtain a structure capable to operate in a wide range of line frequencies, without requiring any additional complex techniques. In this regard, the developed structure is capable to work as a Power Factor Correction (PFC) stage in a wide range of input frequencies $(30 \mathrm{~Hz}-120 \mathrm{~Hz})$ with a Total Harmonic Distortion of the input current $\left(\mathbf{T H D}_{i}\right)$ of less than $2.19 \%$.
\end{abstract}

Keywords - Boost Converter, Discontinuous Conduction Mode (DCM), High Power Factor, MEA, Multipulse Converter, Half-Controlled, Frequency Variations.

\section{INTRODUCTION}

Currently, three-phase AC/DC converters have a wide range of applications for high power systems, such as adjustable-speed drive (ASD), all-electric ships (AES), data centers, power supply for aircraft, wind power plants and, applications in direct current transmission, induction heating, among others. The AC/DC conversion process can be carried out using several techniques and equipment, however, for this process not to lead to the degradation of the Power Factor (PF),

Manuscript received 05/17/2021; first revision 09/19/2021; accepted for publication 11/01/2021, by recommendation of Editor Demercil de Souza Oliveira Jr. http://dx.doi.org/10.18618/REP.2021.4.0011 standards are established to maintain the power quality of the grid [1], [2].

Among the methodologies employed in Power Factor Correction (PFC), to attend to these power quality requirements, are the use of transformers/autotransformer with phase shift associated to bridge rectifiers, which are known as Multipulse Converters [3]-[6]. The main idea of the use of these converters is to take advantage of the angular displacement, provided by the transformers/autotransformers so that the cancellation of certain harmonic components occurs. In general, it is observed that the higher the order of the Multipulse Converters, the lower the characteristic harmonic content of the structure. However, this change usually implies a greater complexity in the transformers' winding construction, as well as greater weight and volume of the final structure.

A possible alternative, in order to avoid the employment of transformers with higher orders, and consequently having more complex windings, is the integration of an active structure, such as a half-controlled (also known as bridgeless) converter (HCC) based on Boost topology, to the traditional 12-pulse rectifier, which allows minimizing the harmonic content presented by the structure and reducing the number of elements conducting in each operation stage [7]. This integration aggregates greater flexibility in the adjustment of the output voltage, which changes not only according to the magnitude of the grid voltage, but also to the duty cycle $(D)$ of the converter and, because it does not employ two controlled switches on the same branch it does not incur the risk of a short circuit on it, making its control and operation simpler.

Although this integration adds some advantages, even with great efforts because of the use of control techniques and synchronization algorithms (PLL), it was verified, the difficulty in order to shape a sinusoidal waveform to the current signal [8]-[10].

During the design stage of the HCCs structures, two main strategies are possible: Operate in continuous conduction mode (CCM) or discontinuous conduction mode (DCM). Choosing the operation mode of the converter to be incorporated is of paramount importance in the specifications of its parameters. In this manner, it is observed that the operation in CCM entails great difficulties in modulating the negative half-cycle of the current, which results not only in significant Total Harmonic Distortion of the input current 


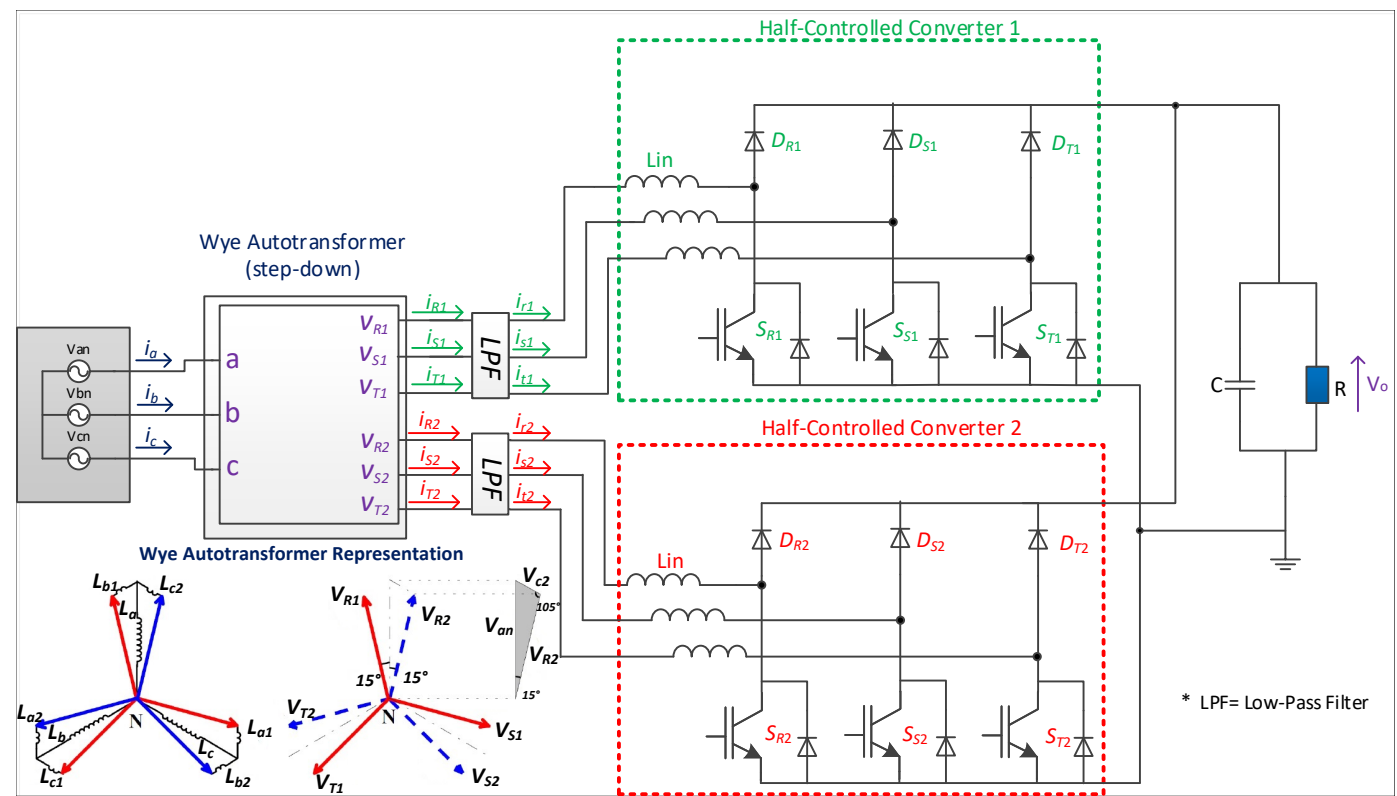

Fig. 1. Proposed 12-pulse converter with two embedded HCC.

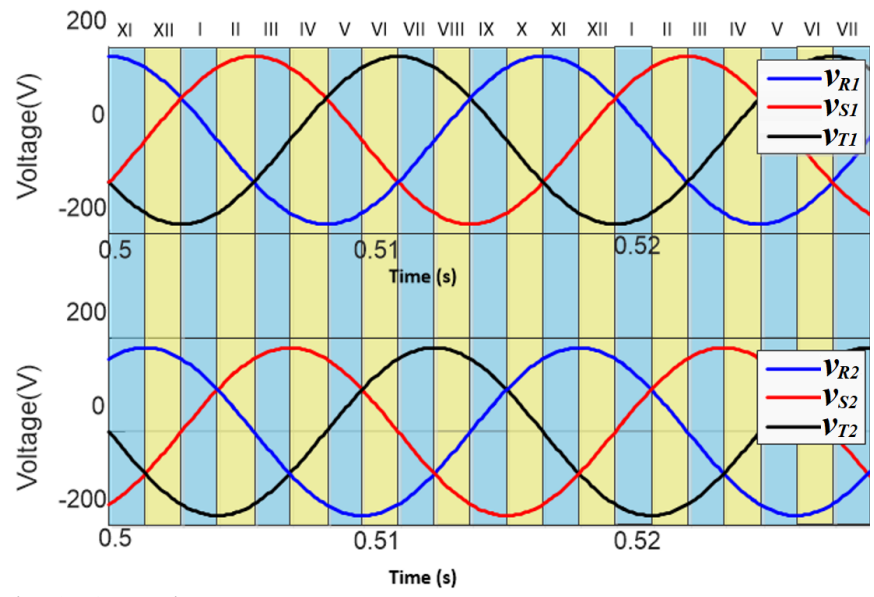

Fig. 2. Operation sectors.

$\left(\mathrm{THD}_{i}\right)$ but also in the presence of even-order harmonic components. This set of characteristics hinders the mitigation of harmonic content and requires a control circuit of greater cost and complexity [8].

The option of operating in the DCM, in turn, presents a favourable characteristic for applying active correction of the power factor: At the end of the switching period, all the energy stored in the inductor is supplied to the load, so that the peak value of the current over the inductor will be proportional to the applied voltage. In other words, the peak of input current naturally tends to follow the input voltage in the discontinuous conduction mode and the switch will begin to conduct with the current value equals to zero, i.e., it will present the ZCS (Zero Current Switching) characteristic, reducing the switching loss.

The incorporation of the HCC operating in the DCM to the traditional 12-pulse rectifier allows taking advantage of the angular displacement, canceling the most significant harmonic components presented by the structure $\left(5^{\text {th }}\right.$ and $\left.7^{\text {th }}\right)$ in this mode of conduction [9], as well as to reduce the complexity of the control circuit, making possible the operation even in an open-loop, commanding all active switches by the same control signal [11].

The 12-pulse converter with two embedded HCC, shown in Fig. 1, presented in computational analysis a $\mathrm{THD}_{i}$ of $1.73 \%$, significantly below the $14 \%$ reported by the one without the active switches, which allows concluding that the incorporation of $\mathrm{HCC}$ can be an alternative to increase the order of pulses, resulting in harmonic content reduction, without incurring a significant increase in the weight, volume and complexity of the final structure [11]. In general, the operation in DCM has the dealing with higher values of peak current in the switches as a downside [12], [13]. The proposed structure, on the other hand, by employing six branches, divides the current stress among each one of them, making the operation in DCM a suitable solution.

The replacement of pneumatic, hydraulic, and mechanical systems with electrical systems has been a trend in more electric aircraft (MEA) and can provide a weight reduction up to $10 \%$ and a consumption reduction of up to $9 \%$ [14]-[16]. The MEA concept has required equipment to operate at growing powers and that are reliable, safe, provides good performance and can operate in faulty conditions [15]. Another challenge provided by applications such as MEA lies in the fact of dealing with a wide range of power frequency variation $(360-800 \mathrm{~Hz})$ [14]. Similarly, in wind turbines (WECS), although it is possible to operate in fixed frequencies, those that can operate in the whole range $(0-100 \%)$ obtain better efficiency rates in the conversion of wind energy into electrical energy [17].

This paper aims to continue the research proposed by [11], by implementing a small-scale prototype and pushing the state of art further, adding the analysis of the impact of power supply frequency variations $(30 \mathrm{~Hz}-120 \mathrm{~Hz})$ in the input current waveform. The possibility of working in a wider range of power supply frequencies combined with its structural advantages make the 12-pulse HCC-embedded converter more attractive for applications with higher requirements for input current harmonic content, meeting, for example, the $\mathrm{THD}_{i}$ 


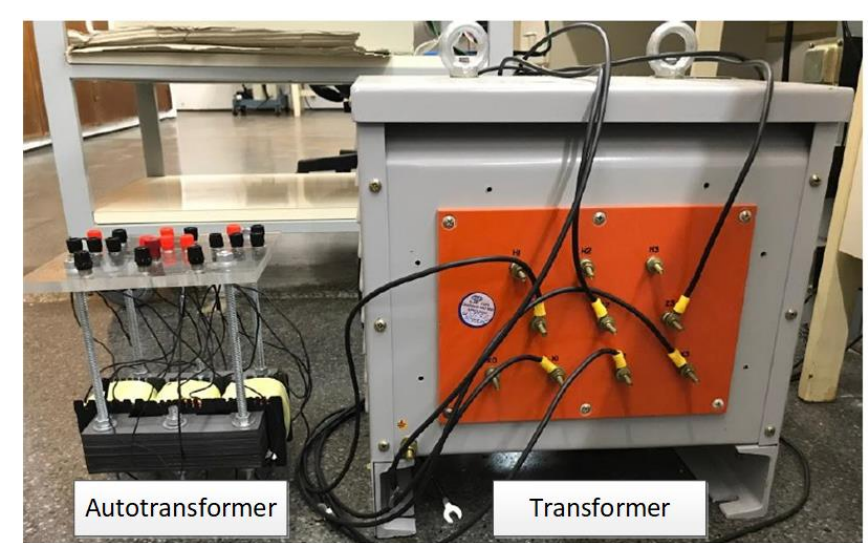

Fig. 3. 12-Pulse Autotransformer vs 12-Pulse Transformer (Size).

criteria established in MIL-STD-704F (for aircraft) [14], [18]. Additionally, it is worth mentioning that the usage of an autotransformer configuration, instead of a transformer, makes possible a significant reduction of the size and weight of the final structure since it processes around one-fifth of total magnetic flux processed by the isolated transformer [19]. In Fig. 3 is shown the comparison between the sizes of the autotransformer (analyzed in this paper) and a transformer, both designed to operate at the same output power.

\section{PROPOSED 12-PULSES CONVERTER WITH 2-HCCS}

In this section the main considerations for the design of the 12-pulse converter with two embedded HCC are presented. As commented, when the proposed structure operates in discontinuous conduction mode provides a series of advantages, once at each end of switching period all the energy stored in the inductor is transferred to the load, i.e., by employing a fixed duty cycle and a switching frequency, significantly greater than grid's voltage frequency, the inductor peak current will be proportional to its voltage, allowing the structure to act as a PFC device without the need for any current control circuitry or current sensing.

In this regard, so as to properly design a converter, it is necessary to address two main issues: Specify the inductor value to guarantee the discontinuous conduction mode; Comprehend the operation stages of the converter. Among the elements that constitute the proposed converter is the twelve-pulses phase shift autotransformer, at low $\mathrm{kVA}$ rating, responsible to provide two sets of three-phase secondary windings, displaced by $30^{\circ}$ from each other, as shown in Fig. 1. The proposed structure takes advantage of the phase shift provided by this autotransformer to cancel the lower order current harmonics $\left(5^{\text {th }}\right.$ and $\left.7^{\text {th }}\right)$ on the primary side.

Once the phase-shift, provided by the 12-pulse autotransformer, cancels the lower order harmonics, the low-pass filters $\left(L_{f} C_{f}\right)$ shown in Fig. 1, have a cutoff frequency equals to one-tenth of the switching frequency $\left(f_{s}\right)$, being responsible to cancel the switching harmonics, making possible to reduce the size of its elements. Thus, the set of voltages that supply both HCC structures are shown in Fig. 2, resulting in 12 cyclically repeated operating sectors (I - XII).

By analyzing the Fig. 2 (Operation sectors), one should notice that each one of the sectors is delimited by one crossing voltage, e.g., the transition from Sector $\mathrm{X}$ to Sector XI is delimited by $v_{T 2}$ crossing from a positive value to a negative one. Once each one of these sectors has its own operation stages, which significantly increases the total number of stages of this structure. For a better understanding of how the secondary voltages affect the operation stages, let us take Sector $\mathrm{X}$ as an example.

Thus, the following analysis presents two transition stages named as "beginning" (transition between Sectors IX and X) and "ending" (transition between sectors X and XI), and the third stage in which all voltages in the secondary winding have a non-null value, named as "Sector X". This analysis neglected the small variations on the secondary voltage during the switching period $\left(T_{S}\right)$.

Beginning: During the charging stage $\left(D T_{S}\right)$ show in Fig. 4(a), although the same control signal was sent to all controlled switches (same control signal to both $\mathrm{HCCl}$ and HCC2), the voltage $v_{T 1}$ has null voltage during this stage, resulting in a null current in the elements connected to its branch. Thus, the charging stage for HCC1 will happen as follows: The switch $S_{R 1}$ is directed polarized and has received the control signal, making a positive current flowing through $L_{R 1}$, and returning through $L_{S 1}$. With regard to HCC2 the voltages $v_{R 2}$ and $v_{T 2}$ are positive, making respectively switches $S_{R 2}$ and $S_{T 2}$ directed polarized and two currents $i_{r 2}$ and $i_{t 2}$ flowing through these switches and returning by the diode connected to $L_{S 2}$, which is connected to a secondary winding having a negative voltage.

During the discharging stage, all energy stored in the inductors will be transfer to the load, and the output capacitor (C). The equivalent circuitry for this stage is shown in Fig. 4(b). Once the energy stored in the inductors is transferred, a dead time will occur as shown in Fig. 4(g).

During Sector X: During this stage, all secondary windings have a non-null voltage, i.e., every branch of both HCC's will have one semiconductor (controlled switch or diode) conducting during the charging stage $(D T)$, whose equivalent circuitry is shown in Fig. 4(c), and its discharging stage is shown in Fig. 4(d). Once the proposed converter operates in DCM, analogously to the previous case, after the discharging stage, all inductors will have null current and its circuitry will be as shown in Fig. $3(\mathrm{~g})$.

Ending: At the ending stage, the $v_{T 2}$ voltage has a null-value therefore, the $\mathrm{HCC} 2$ will present a behavior likewise the one present by $\mathrm{HCC} 1$ at "the beginning", having three operational stages shown in Fig. 4(e)-(g). By analyzing Fig. 2 (Operation sectors) it is possible to evaluate the moments when each HCC structure is subject to the maximum voltage (line voltage) and, once it acts as a PFC, when it is subject to the maximum current, providing means to the designer to specify the inductor present on them.

Taking the transition between Sector VI to VII, the $v_{T 1}$ voltage is in its maximum value and both $v_{R 1}$ and $v_{S 1}$ have the same value and opposite signal of $v_{T 1}$, thus the equivalent circuitry for the charging stage $\left(D T_{s}\right)$ for those conditions is shown in Fig. 5(a). Additionally, by neglecting the non-idealities of the switches, one should obtain the equivalent circuit shown in Fig. 5(b), where an equivalent inductance $\left(L_{\text {boost }}\right)$ for an HCC, under these conditions, may be expressed 


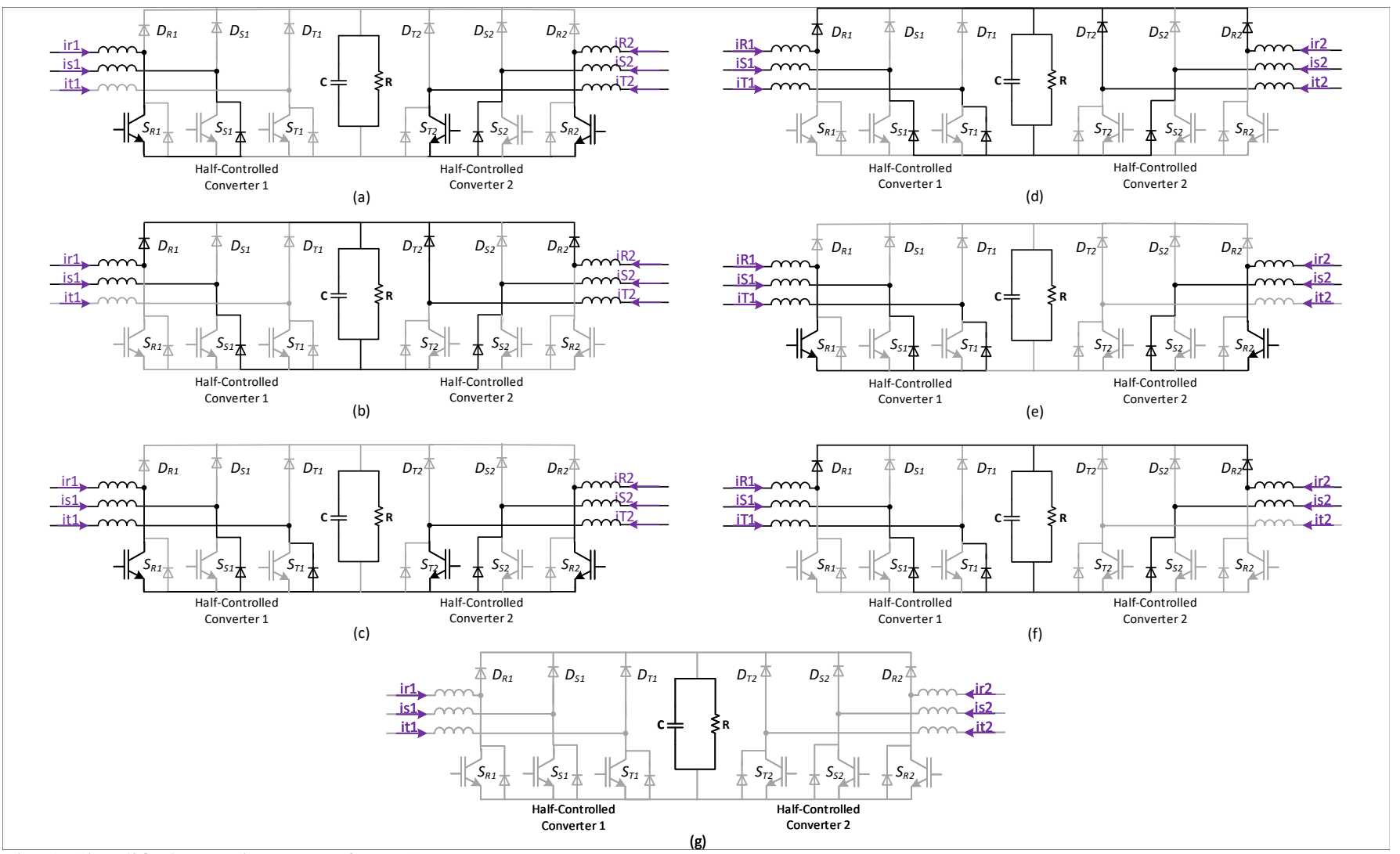

Fig. 4. Simplified operation stages for X Sector.

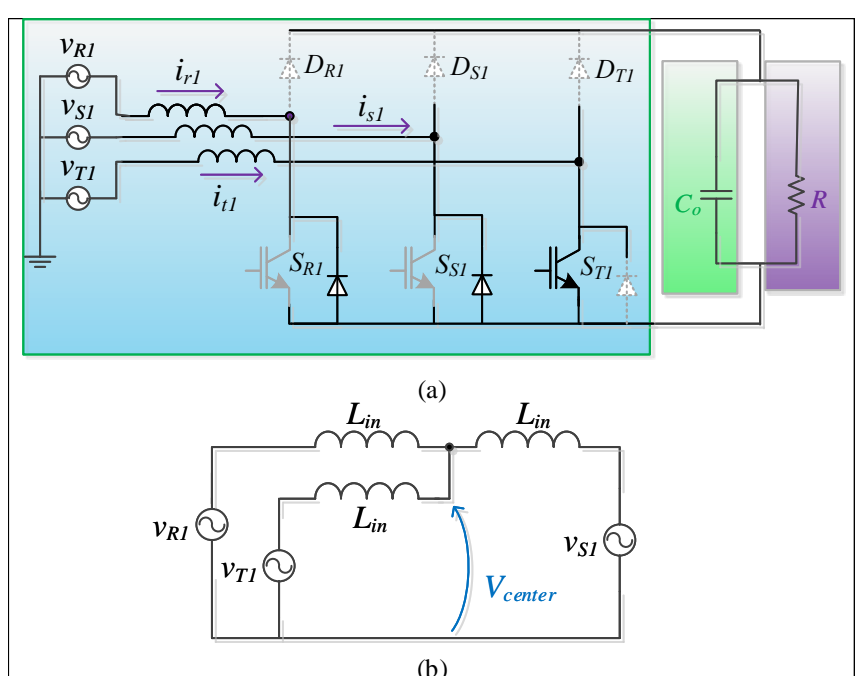

Fig. 5. Charging state (DT) in Sector X: (a) Equivalent Circuit; (b) Simplified Circuit.

as follows in (1).

$$
L_{\text {boost }}=\frac{3}{2} L_{\text {in }}
$$

Once this converter operates as a PFC, the current in each inductor is proportional to the voltage applied to it, making the instant of maximum voltage also the instant of maximum current. Considering the set of voltages supplying both HCC's, and the characteristics described, the currents in the inductors will follow (2) and (3).

$$
\begin{aligned}
& i_{r_{1}}(t)+i_{s_{1}}(t)+i_{t_{1}}(t)=0 \\
& i_{r_{2}}(t)+i_{s_{2}}(t)+i_{t_{2}}(t)=0
\end{aligned}
$$

Even so, to providing flexibility in the regulation of the output voltage (by adjusting the duty cycle), the proposal of the structure also adds the possibility of using a very simpler control logic, to deal with power supply frequency variations, although this does not imply a compulsory requirement. Among the possible logic, the same pulse (without any discrepancies) can be sent to all active switches, simultaneously, with no degradation of the input current parameters.

To design the inductors, first, it is desirable to understand how the operation steps of the converter are obtained. Considering the characteristics of the power system, the converter features 12 cyclically repeating sectors, as shown in Fig. 2, each one enabling a set of operation steps, that are shown in Fig. 4.

The delimitation of the sectors is given when there is the reverse direction of one of the voltages that occurs in the secondary winding. The sectors are listed sequentially from I to XII. It should noticed that the switching period $T_{S}$ is much smaller than a given sector duration (e.g. Sector $\mathrm{X}$ ), thus the stages of a converter working in DCM will be seen multiple times in every given sector.

Another important issue is that the value of the voltage varies during the sectors, e.g., voltage $V_{T 2}$ starts with a positive value, at the beginning of Sector $X$, and at the end has its value equal to zero, which add more possible operation steps (like 


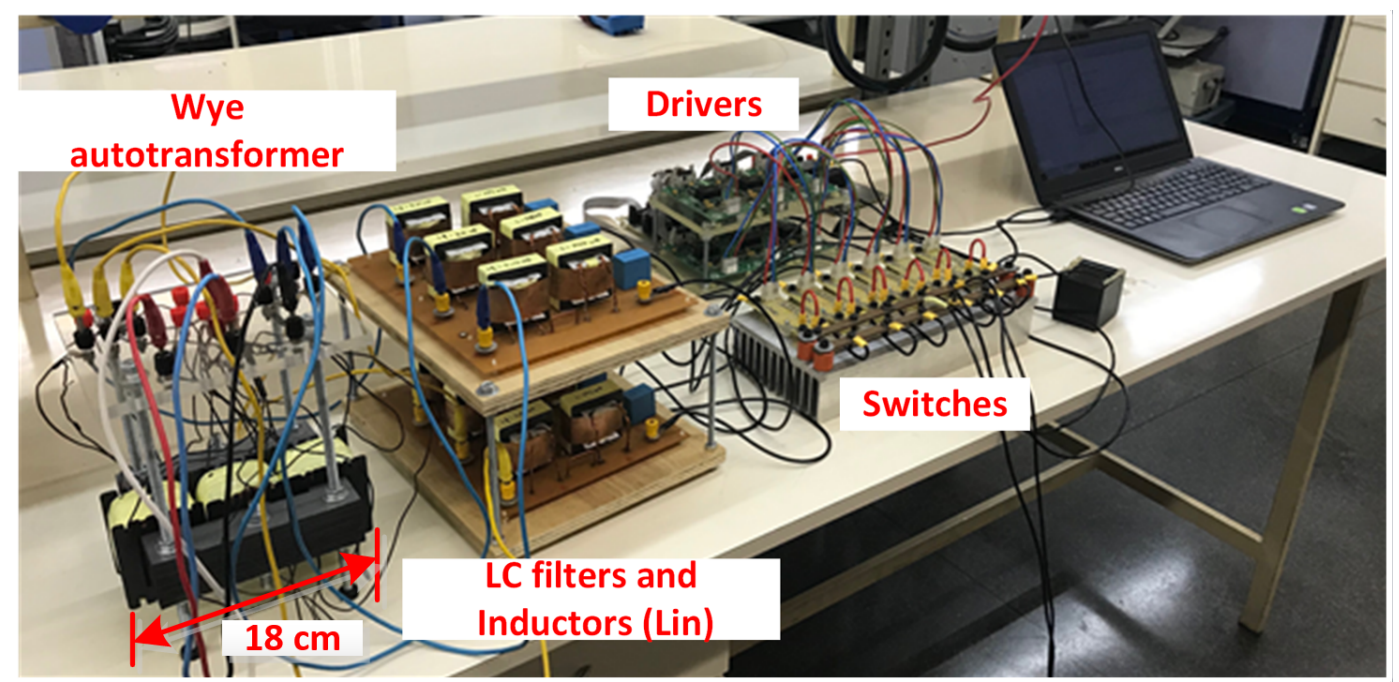

Fig. 6. Experimental set-up.

the ones shown in Fig. 4) in this sector.

Considering the number of sectors, to analyze the operation steps, Sector X was taken as an example. By analyzing the steps (a) to (g) presented in Fig. 4, a good understanding of the converter operation is obtained. It should be noted that the converter acts as PFC, so the voltage $v_{R 1}$ and the envelope of the current $i_{r 1}$ have the same phase.

To properly specify the inductors for the set of cyclically repeated conditions, one should consider two main issues: The maximum line voltage applied to the HCC's $\left(V_{L_{p k}}\right)$ and the peak value of inductor current $\left(I_{p k}\right)$. The parameter $\alpha$ is determined by the quotient between the peak value of line voltage $\left(V_{L_{p k}}\right)$ with the output voltage $\left(V_{o}\right)$ as shown in (4):

$$
\alpha=\frac{V_{L p k}}{V_{o}}
$$

During the charging stage, each $\mathrm{HCC}$ is compound by a set of three inductors that will be storing energy. To ensure that they will operate in DCM, the design of the inductance must consider the maximum value of the current in this set of inductors. Thus, the inductance $L_{i n}$ must obey (5).

$$
L_{i n}<\frac{2}{3} \frac{V_{L p k}^{2}}{2 \pi f_{s} \frac{P_{o}}{2}} \frac{(1-\alpha)^{2}}{\alpha} \sqrt{3\left(Y_{o}(\alpha)^{2}\right)}
$$

Where $P_{o}$ is the output power, $f_{S}$ is the switching frequency and the $Y_{o}$ is determined by (6).

$$
Y_{0}(\alpha)=-2-\frac{\pi}{\alpha}+\frac{2}{\alpha \sqrt{1-\alpha^{2}}}\left(\frac{\pi}{2}+\tan ^{-1}\left(\frac{\alpha}{\sqrt{1-\alpha^{2}}}\right)\right)
$$

\section{EXPERIMENTAL RESULTS}

Some power applications, such as MEA (More Electric Aircrafts), must deal with a wide range of power supply frequencies at the same time they have to meet to the $\mathrm{THD}_{i}$ standards. Having these criteria into account, this section aims to verify if the proposed structure presents itself as a suitable solution for applications which requires the possibility to deal with a wide range of power supply frequencies.

For this analysis, the reference was made to an application in which the input frequency varies over a wide range of values. A small-scale prototype was made, shown in Fig. 6, operating in the power supply voltage range from $30 \mathrm{~Hz}$ to $120 \mathrm{~Hz}$. The main parameters of the analyzed converter are shown in Table I.

\section{TABLE I}

Main parameters for the frequency variation analysis

\begin{tabular}{lc}
\hline Parameter & Value \\
\hline \hline$C$ - Output capacitor & $100 \mu \mathrm{F}$ \\
\hline$C_{f}$ - Low-pass filter capacitance & $3.3 \mu \mathrm{F}$ \\
\hline$L_{f}$ - Low-pass filter inductance & $2 \mathrm{mH}$ \\
\hline$f_{\text {in }}$ - Input frequency range & $30-120 \mathrm{~Hz}$ \\
\hline$f_{s}$ - Switching Frequency & $20 \mathrm{kHz}$ \\
\hline$L_{\text {in }}$ - HCC Inductor & $200 \mu \mathrm{H}$ \\
\hline$P$ - Load power & $800 \mathrm{~W}$ \\
\hline$R$ - Equivalent load resistance & $200 \Omega$ \\
\hline$P_{o}$ - Nominal output power & $1400 \mathrm{~W}$ \\
\hline Autotransformer Step-down factor & 0.896 \\
\hline$V_{i}$ - Supply rms phase voltage & $84 \mathrm{VAC}$ \\
\hline$V_{o}$ - Output voltage & $400 \mathrm{VDC}$ \\
\hline$D$ - Nominal duty cycle & 0.33 \\
\hline Branch switches model & SK 35 GAL
\end{tabular}

The proposal converter employs a Wye step-down autotransformer (auto-connected), which supplies the HCC bridges with $127 \mathrm{~V}$ (rms line voltage). To verify the behavior of the proposed structure under power frequency variations, all the results presented in Figs. 7(a)-(e) employed an 800W load and are displayed at the same time basis, making easier the comparison between the displayed cases.

By analyzing Figs. 7(a)-(g) and the detail presented in Fig. 7(f), one can see that the structure was able to act as PFC, i.e., the line current presents the waveform very close to a sinusoidal shape (voltage waveform), maintaining its symmetry and appropriate phase displacement, without requiring any adjustment on its parameters (same set-up for 

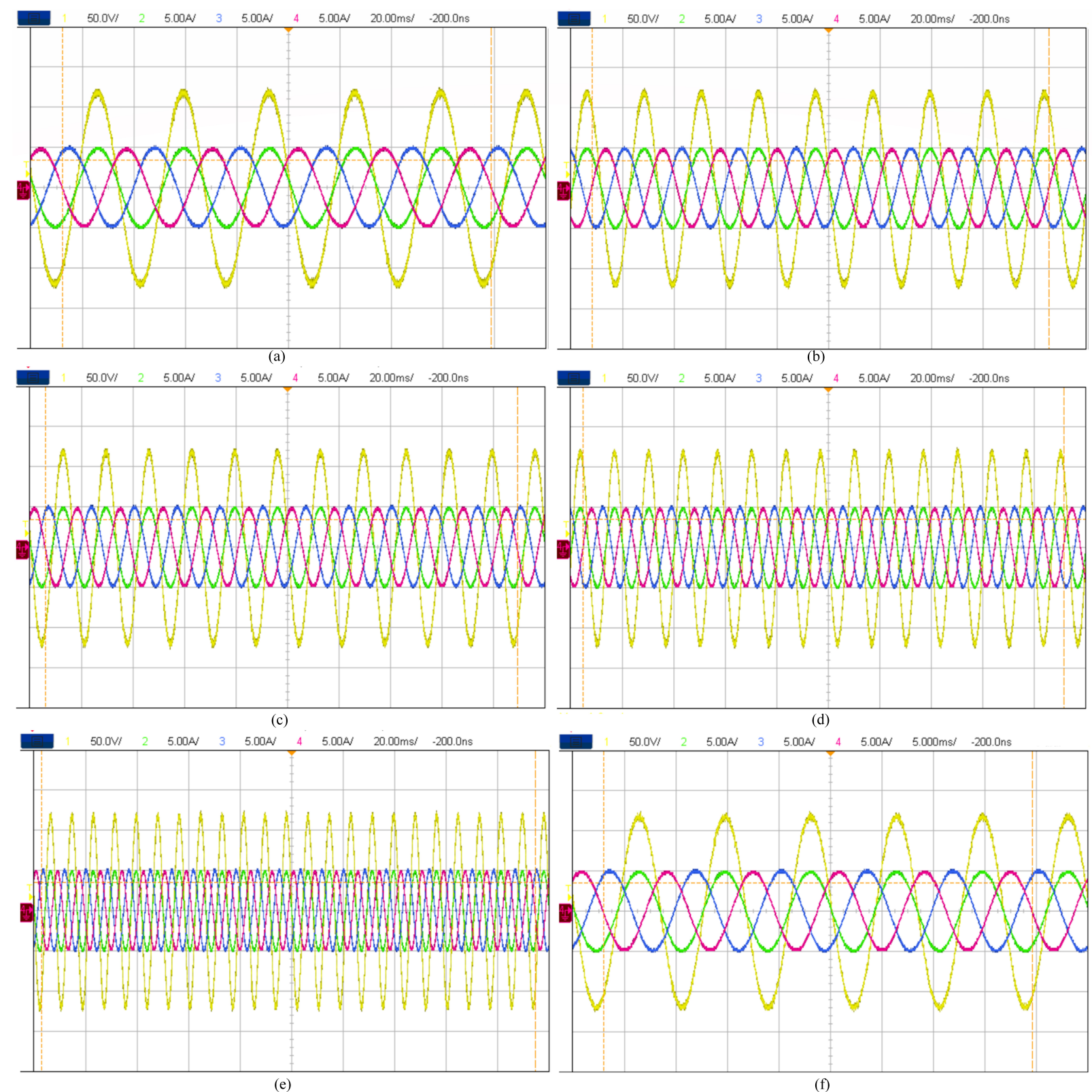

Fig. 7. Main waveforms of at the grid side, for different input frequency. $v_{c n}$ (yellow), $i_{a}$ (red), $i_{b}$ (blue), $i_{c}$ (green): (a) $30 \mathrm{~Hz}$; (b) $45 \mathrm{~Hz}$; (c) 60 $\mathrm{Hz}$; (d) $75 \mathrm{~Hz}$; (e) $120 \mathrm{~Hz}$; (f) Detail of the $120 \mathrm{~Hz}$ waveforms.

all cases).

Due to its characteristics, the proposed converter did not require the use of any current loop control, neither required any phase displacement between pulses. In this regard, the employed control strategy is based on a single-loop voltage control, where the control-to-output transfer function $G_{v d}$ of the proposed structure can be approximated to the traditional three-phase Boost converter transfer function operating in DCM, as described by (7).

$$
G_{v d}(s)=\frac{G_{v d 0}}{1+\frac{s}{\omega_{p}}}
$$

where

$$
G_{v d 0}(s)=\frac{2 V_{o}}{D}\left(\frac{M-1}{2 M-1}\right)
$$

$$
\omega_{p}=\frac{2 M-1}{(M-1) R C}
$$

and $M$ is the static gain in DCM, expressed by (10).

$$
M=\frac{1+\sqrt{1+\frac{4 R D^{2}}{f_{s} L_{\text {boost }}}}}{2}
$$

Thus, from Table I, the bode diagram of the transfer function $G_{v d}$, including the gain sensor $H=2.5 / 400 \mathrm{~V} / \mathrm{V}$, is illustrated in Fig. 8 (curve blue in color). Then, a PI controller was adopted for the control design and, as shown in Fig. 8 (yellow in color), by using a proportional gain $K_{p}=0.09$ and an integral gain $K_{i}=38.34$, a crossover frequency $f_{c}=20 \mathrm{~Hz}$ and phase margin $P M=86^{\circ}$ are achieved from the open-loop voltage control. 


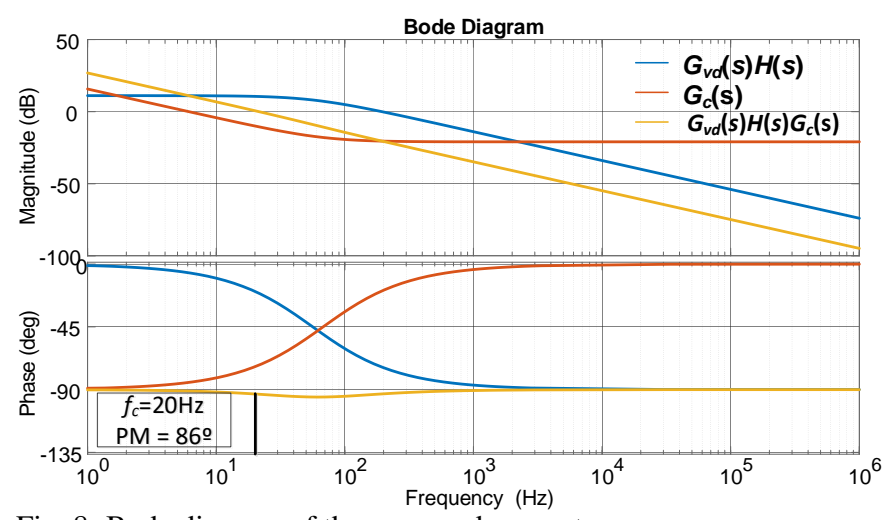

Fig. 8. Bode diagram of the proposed converter.
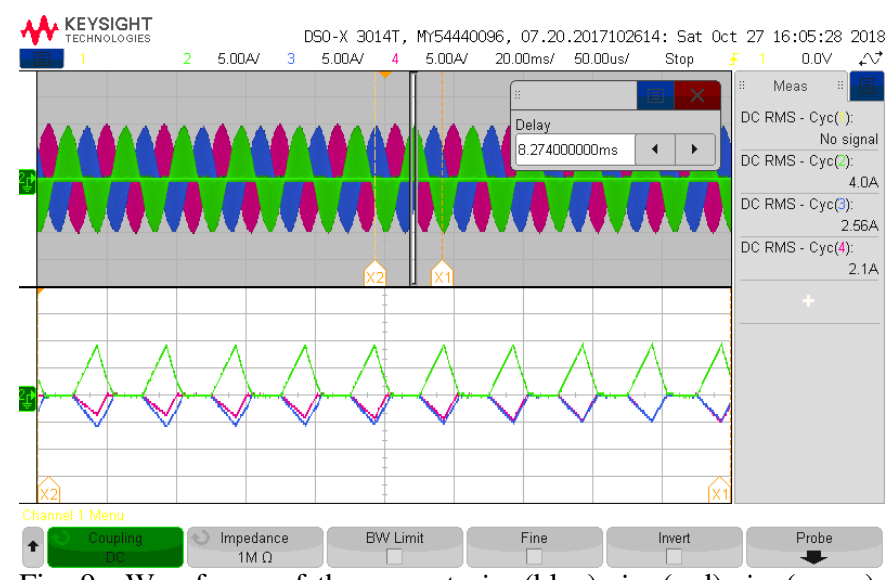

Fig. 9. Waveforms of the currents $i_{r 1}$ (blue), $i_{s 1}$ (red), $i_{t 1}$ (green) for $60 \mathrm{~Hz}$ input frequency and the detail of the waveforms when the maximum value of $i_{t 1}$ occurs.

It should be noted that the cutoff frequency of the LC filter is one-tenth of $f_{s}$ (the switching frequency is equal to $20 \mathrm{kHz}$ ). The employed autotransformer is responsible to cancel the $5^{\text {th }}$ and $7^{\text {th }}$ order harmonics, thus, the LC filter is not as bulky as those commonly employed in traditional 12 pulse converters. Once the waveform of the grid currents is obtained, it should verified the behavior of the currents $i_{r 1}, i_{s 1}$, and $i_{t 1}$. The waveforms for a $60 \mathrm{~Hz}$ input frequency, are shown in Fig. 9.

By analyzing Fig. 9 one can see that in fact, the inductors currents obey the logic expressed in (2) and (3), in other words, at a given moment the sum of the currents belonging to the same HCC is equal to zero. Comparing Fig. 9 and Fig. 10, one should notice that after the LC filter influence, the currents in the secondary winding are not pulsed but their waveform although closer to a sinusoidal wave, still have some harmonic components (mainly the $5^{\text {th }}$ and $7^{\text {th }}$ harmonics).

The waveforms of the currents $i_{R 1}, i_{S 1}$ and $i_{T 1}$ are shown in Fig. 10 along with the grid line voltage $v_{S T}$. It is important to note that although the phase supply voltage $\left(V_{i}\right)$ is equal to $84 \mathrm{~V}$, because the configuration employed (Wye step-down), the rms value of the line voltage $\left(V_{L}\right)$ in the secondary will respect (11).

$$
V_{L}=V_{i} \sqrt{3}(0.896)
$$

Once the main waveforms of the converter were shown, it is desired to verify how the curve relating the harmonic distortion and load is given. For this test, the converter was

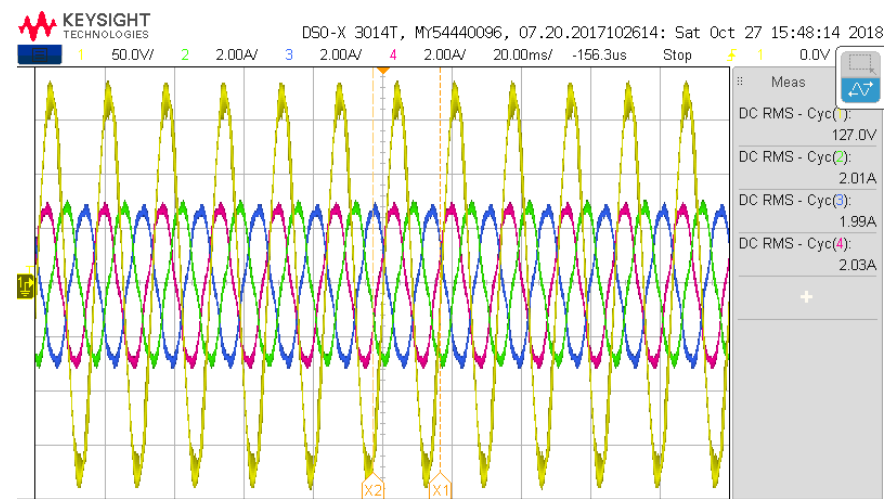

Fig. 10. Currents $i_{R 1}$ (blue), $i_{S 1}$ (red), $i_{T 1}$ (green) and $v_{S T}$ (yellow) Voltage.

\section{THDi x Load}

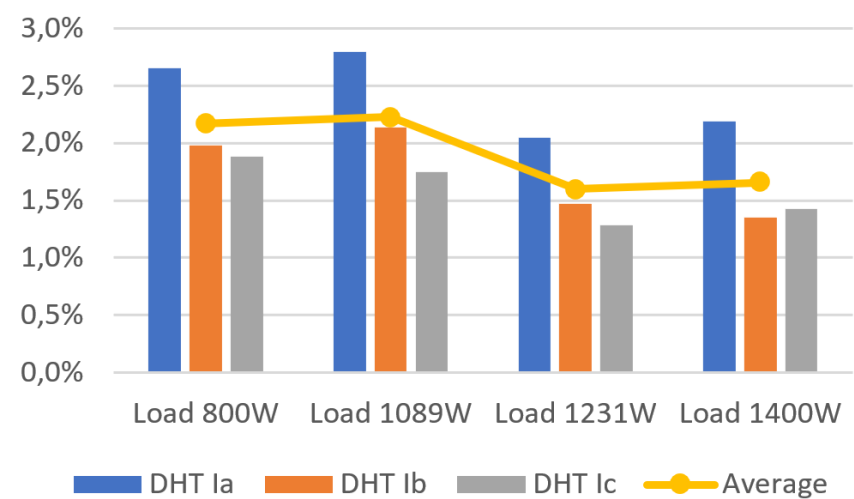

Fig. 11. THD $_{i}$ behavior vs load power.

supplied with an input frequency of $60 \mathrm{~Hz}$ for all measured points. The curve relating $\operatorname{THD}_{i}$ (Total Harmonic Distortion of the current) and Load is shown in Fig. 11.

When analyzing the curves shown in Fig. 11, it can be verified that the structure presented a significantly reduced harmonic content, $2.19 \%$ in nominal conditions (Ia), when compared to the $14 \%$ of the traditional structure, also meets the criterion of $\mathrm{THD}_{i}$ of the MIL-STD-704F, which establishes that the $\mathrm{THD}_{i}$ must be below $5 \%$.

\section{CONCLUSION}

The results presented in this work allow us to conclude that the 12-pulse converter with embedded HCC bridge presents the possibility of higher power factor operation over a wide power frequency range, using only a single-loop voltage control scheme.

In addition to the possibility of measuring only the output voltage, the driver circuit sends the same command signal to the switches, without the need for phase shift and, due to the structural characteristics of the converter, the active switches are all in the same reference, which corroborates the design simplicity of the command circuitry.

These features, provided by the intrinsic characteristics of the structure, allow the designer to reduce the number of sensors required since there is no need measure the input currents as well as the reduction of the computational cost, 
since the structure can operate only with the voltage loop control.

The results presented by the small-scale prototype allow us to conclude that the proposed structure was able to operate, as a PFC, in a wide range of power supply frequencies $(30 \mathrm{~Hz}$ up to $120 \mathrm{~Hz}$ ), which makes the structure a possible alternative for applications in which the power frequency can vary in a substantially.

Naturally, for each application where it is desired to employ the proposed converter, it is necessary to consider the range of frequencies in which the converter will be subjected since these parameters are directly related to the autotransformer design and, the parameters of the HCC bridges.

When analyzing how the $\mathrm{THD}_{i}$ behavior in function of the load, it can be verified that the structure presents reduced $\mathrm{THD}_{i}$ less than $5 \%$ for all analyzed cases. These results allow concluding that the incorporation of the HCC bridges to the 12-pulse autotransformer, is an alternative to the use of higher-order converters, which implies reducing the complexity of the final structure. Besides, by using the autotransformer configuration, the magnetic flux processed by it will be around one-fifth of the one processed by the isolated transformer, resulting in a significant reduction of the weight and size of this element.

Given the numerous features described, such as high robustness, simplicity of design, switch command logic that does not require any sensors, PLL, having all control switches in the same reference and ZCS switching of semiconductors guaranteed, and the possibility to operate with the variable input frequency. The authors understand that this structure can become a strong candidate in three-phase applications with variable frequency, such as Wind Generation, MEA, Electric Traction, among others.

\section{ACKNOWLEDGEMENTS}

The authors wish to thank the Federal Institute of São Paulo (Instituto Federal de São Paulo - IFSP), the São Paulo Research Foundation (FAPESP) and the São Paulo State University (UNESP), which provided resources and all the structure that enabled this work to be carried out. This research was supported in part by the Coordenação de Aperfeiçoamento de Pessoal de Nível Superior - Brasil (CAPES) - Finance Code 001 and the São Paulo Research Foundation - FAPESP Grant No. 2015/15872-9.

\section{REFERENCES}

[1] IEEE, "IEEE Recommended Practice and Requirements for Harmonic Control in Electric Power Systems", IEEE Std 519-2014 (Revision of IEEE Std 519-1992), pp. 1-29, 2014.

[2] IEC, "Electromagnetic compatibility (EMC) - Part 3-2: Limits - Limits for harmonic current emissions (equipment input current $16 \mathrm{~A}$ per phase)", IEC 61000-3-2:2018, pp. 1-73, 2018.

[3] D. Paice, I. I. A. Society, Power Electronic Converter Harmonics: Multipulse Methods for Clean Power, IEEE Press, 1996.

[4] B. Singh, S. Gairola, B. N. Singh, A. Chandra, K. Al-Haddad, "Multipulse AC-DC Converters for
Improving Power Quality: A Review", IEEE Transactions on Power Electronics, vol. 23, no. 1, pp. 260-281, 2008.

[5] S. P. P., R. Kalpana, B. Singh, G. Bhuvaneswari, "A 20-Pulse Asymmetric Multiphase Staggering Autoconfigured Transformer For Power Quality Improvement", IEEE Transactions on Power Electronics, vol. 33, no. 2, pp. 917-925, 2018.

[6] D. L. Mon-Nzongo, P. G. Ipoum-Ngome, T. Jin, J. Song-Manguelle, "An Improved Topology for Multipulse AC/DC Converters Within HVDC and VFD Systems: Operation in Degraded Modes", IEEE Transactions on Industrial Electronics, vol. 65, no. 5, pp. 3646-3656, 2018.

[7] Y. Wang, D. Panda, T. A. Lipo, D. Pan, "Performance improvement of dual-half-controlled-converter and its applications in utility rectifiers", in 8th International Conference on Power Electronics - ECCE Asia, pp. 1711-1718, 2011.

[8] M. M. Reis, B. Soares, L. H. S. C. Barreto, E. Freitas, C. E. A. Silva, R. T. Bascope, D. S. Oliveira, "A variable speed wind energy conversion system connected to the grid for small wind generator", in 2008 Twenty-Third Annual IEEE Applied Power Electronics Conference and Exposition, pp. 751-755, 2008.

[9] D. S. Oliveira, L. H. S. C. Barreto, F. L. M. Antunes, M. I. B. V. Silva, D. L. Queiroz, A. R. Rangel, "A DCM three-phase high frequency semi-controlled rectifier feasible for low power WECS based on a permanent magnet generator", in 2009 Brazilian Power Electronics Conference, pp. 1193-1199, 2009.

[10] D. S. Oliveira, Jr., M. M. Reis, C. E. A. Silva, L. H. S. Colado Barreto, F. L. M. Antunes, B. L. Soares, "A Three-Phase High-Frequency Semicontrolled Rectifier for PM WECS", IEEE Transactions on Power Electronics, vol. 25, no. 3, pp. 677-685, 2010.

[11] J. C. Pelicer, F. J. M. de Seixas, A. C. de LourenÃ §o, L. Silva, "Novel isolated multi-pulse rectifiers with low current distortion using three-phase half-controlled boost converters", in 2015 IEEE 13th Brazilian Power Electronics Conference and 1st Southern Power Electronics Conference (COBEP/SPEC), pp. 1-5, 2015.

[12] M. H. Granza, R. Gules, C. H. Illa Font, "Hybrid and Three-Level Three-Phase Rectifiers Using Interleaved DCM Boost Converters", IEEE Access, vol. 7, pp. 160168-160176, 2019, doi:10.1109/ACCESS.2019. 2951123.

[13] S. Gangavarapu, A. K. Rathore, "Three-Phase Buck-Boost Derived PFC Converter for More Electric Aircraft", IEEE Transactions on Power Electronics, vol. 34, no. 7, pp. 6264-6275, 2019, doi:10.1109/ TPEL.2018.2877509.

[14] J. Chen, X. Zhang, C. Wen, "Harmonics Attenuation and Power Factor Correction of a More Electric Aircraft Power Grid Using Active Power Filter", IEEE Transactions on Industrial Electronics, vol. 63, no. 12, pp. 7310-7319, 2016. 
[15] K. Rajashekara, "More Electric Aircraft Trends [Technology Leaders]", IEEE Electrification Magazine, vol. 2, no. 4, pp. 4-39, 2014.

[16] J. Benzaquen, M. B. Shadmand, A. Stonestreet, B. Mirafzal, "A unity power factor active rectifier with optimum space-vector predictive DC voltage control for variable frequency supply suitable for more electric aircraft applications", in 2018 IEEE Applied Power Electronics Conference and Exposition (APEC), pp. 1455-1460, 2018.

[17] V. Yaramasu, B. Wu, P. C. Sen, S. Kouro, M. Narimani, "High-power wind energy conversion systems: State-of-the-art and emerging technologies", Proceedings of the IEEE, vol. 103, no. 5, pp. 740-788, 2015.

[18] D. of Defense, "AIRCRAFT ELECTRIC POWER CHARACTERISTICS", MIL-STD-704 Rev F, 2004.

[19] F. J. M. d. Seixas, Conversores CA-CC de 12 $K W$ com elevado fator de potencia utilizando autotransformador com conexao diferencial de multiplos pulsos, Ph.D. thesis, Universidade Federal de Santa Catarina, Centro Tecnologico. Programa de Pos-Graduacao em Engenharia Eletrica, 2001.

\section{BIOGRAPHIES}

João Carlos Pelicer Junior, was born in São Paulo, SP, Brazil, in 1989. He received a B.S. degree in Electrical Engineering from São Paulo State University (UNESP) in 2012, where he also obtained M.S. and Ph.D. degrees in 2014 and 2019, respectively. He is currently a Professor at the Federal Institute of São Paulo (IFSP). His research interest includes high-power factor rectifiers, multipulse converter applications, power factor correction, and switching converters.
Angelo César de Lourenço, was born in Maringá, Brazil, in 1976. He received a B.S. degree in Electrical Engineering from the Federal University of Mato Grosso do Sul, UFMS, Campo Grande, in 1998, the M.S. degree in Electrical Engineering from Universidade Estadual Paulista, UNESP in 2001, where he also obtained a Ph.D. in 2016. Currently he is a Professor at the Federal Institute of Mato Grosso do Sul, IFMS, Campo Grande since 2010. His research interests include electrical power factor correction, renewable energy, electric machines and drives.

Luis De Oro Arenas, was born in Cartagena de Indias, Colombia. He received the B.Sc. degree in electronic engineering from the National University of Colombia, Bogotá D.C, Colombia, in 2012, and the M.Sc. and Ph.D. degrees in electrical engineering from São Paulo State University (UNESP), Ilha Solteira (SP), Brazil, in 2014 and 2019 , respectively. He is currently a postdoctoral fellow with the Group of Automation and Integrated Systems, São Paulo State University (UNESP), Sorocaba (SP), Brazil. His current research interests include power electronics, power quality, power theories, smart-metering, and microgrids.

Falcondes José Mendes de Seixas, was born in Jales, SP, Brazil. He received the B.S. degree in electrical engineering from the Engineering School of Lins, Lins, Brazil, in 1988 and the M.S. and Ph.D. degrees in electrical engineering from the Federal University of Santa Catarina, Florianpolis, Brazil, in 1993 and 2001, respectively. He is currently an Assistant Professor at the Department of Electrical Engineering, São Paulo State University (UNESP), Ilha Solteira, Brazil. His research interests include high-power factor rectifiers, three-state switching cell and multi-pulse converter applications. 